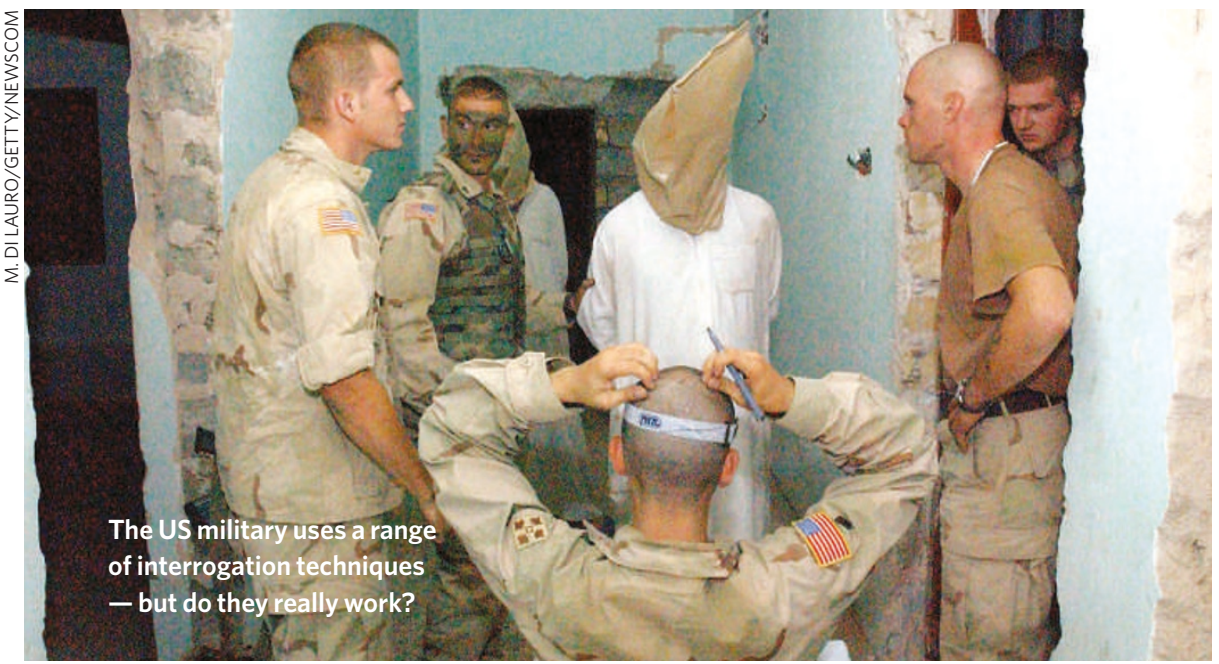

\title{
Interrogation comes under fire
}

\section{WASHINGTON DC}

There is no scientific basis for current interrogation techniques, a US government-funded study has found. The report has stirred up controversy by calling for more research into the matter, angering many psychiatrists who believe such work is unethical.

The 374-page study on "educing information" was conducted by the Intelligence Science Board, an independent panel that advises the government's intelligence agencies. The report concludes that "virtually none of the interrogation techniques used by US personnel over the past half-century have been subjected to scientific or systematic enquiry or evaluation".

First published in December, the report became public last week after it was leaked to the Federation of American Scientists, a watchdog group based in Washington DC. Members of the study group declined to comment, citing the sensitive nature of their work.

The report provides a comprehensive review of military and law-
"We have not done very well in the absence of research." testimonials of former US prisoners of war to understand whether and how torture worked on them. Finally, it calls for controlled studies on soldiers undergoing survival training and on college students willing to participate in "benign" research.

Such studies might be useful if they are conducted safely and ethically, says Steven Aftergood of the Federation of American Scientists. He points out that regardless of scientists' position on the matter, US soldiers and intelligence officers seem to be engaging in harsh interrogation practices in Iraq, Afghanistan and at Guantanamo Bay in Cuba, so they need to know what works, and what doesn't. "We have not done very well in the absence of research," he says.

Others disagree. "I doubt very much that enforcement interrogation techniques and finds numerous misperceptions, both within and outside professional circles. For example, it concludes that the belief that torture breaks down a subject's resistance is without technical merit, as is the effectiveness of strategies such as sleep deprivation. It also finds that professional interrogators have as many erroneous beliefs as novices about how to use body language to spot liars, and concludes that current lie-detection technology is still highly unreliable.

In a controversial final chapter, the report calls for a systematic investigation of interrogation techniques to determine which yield the best information, and suggests reviewing the any research could be done in a university setting or that any ethical person would do it," says Alan Stone, a psychiatrist at Harvard University in Cambridge, Massachusetts. Stone points out that interrogation is often designed to induce stress, and that raises a host of "intractable" ethical issues, such as how to gain consent from study subjects.

The fields of psychology and psychiatry are split over whether to carry out such work. In 2005, the American Psychological Association stated that psychologists could participate in interrogation, but not torture. The American Psychiatric Association, meanwhile, has condemned any such work by its members. Gregg Bloche, a lawyer and psychiatrist at Georgetown University in Washington DC, says: "This underscores the need to make some rules." Geoff Brumfiel
ON THE RECORD

\section{c(Of all the places to make artificial snow, this has to be the most absurd.》}

Jonathan Loh, co-author of a report by environmental group WWF showing that citizens of the United Arab Emirates, the desert destination for indoor snowboarding, have the largest ecological footprints in the world.

\section{NUMBER CRUNCH}

$\mathbf{5 2 4}$ Nobel prizewinners and nominees from 1901 to 1950 were included in a University of Warwick survey of their average longevity.

75.8 was the average lifespan of the unlucky also-rans.

77.2 was the average longevity of the winners, suggesting that receiving a Nobel boosts more than just your career.

\section{SCORECARD}



Cigarette companies The amount of nicotine inhaled by the average smoker increased by $11 \%$ between 1998 and 2005, research shows, because cigarettes now contain higher levels of the drug.

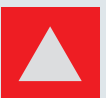

Quitting smoking But smokers might be able to kick the habit more easily than before with the help of varenicline, a recently licensed drug that seems to treble the odds of successfully quitting, according to early data.

\section{ZOO NEWS}

Surprised staff at the Chimp Haven sanctuary in Shreveport, Louisiana, are to carry out a paternity test after one of the females, Teresa (pictured), unexpectedly gave birth this month - despite the males all having been given a vasectomy.

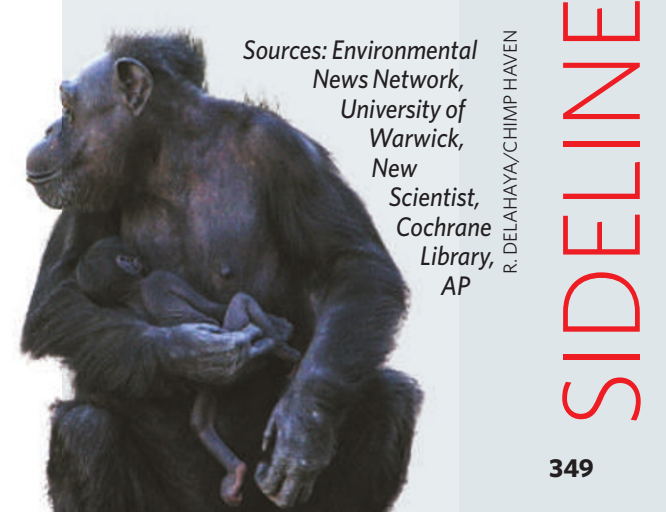

